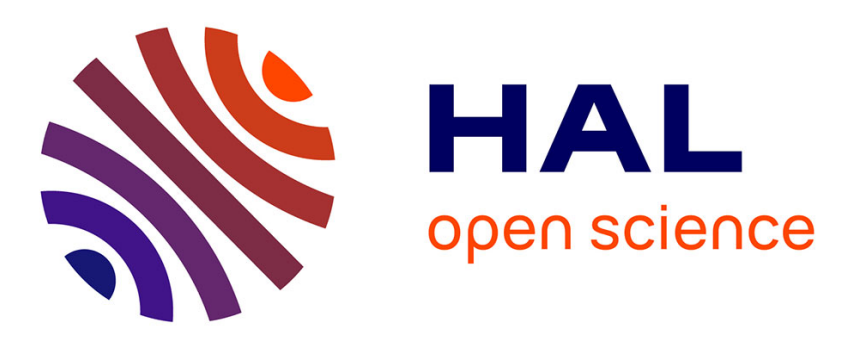

\title{
Positron annihilation characteristics in UO_2: For lattice and vacancy defects induced by electron irradiation
}

M.-F. Barthe, H. Labrim, A. Gentils, P. Desgardin, C. Corbel, S. Esnouf, J.P. Piron

\section{To cite this version:}

M.-F. Barthe, H. Labrim, A. Gentils, P. Desgardin, C. Corbel, et al.. Positron annihilation characteristics in UO_2: For lattice and vacancy defects induced by electron irradiation. physica status solidi (c), 2007, 4 (10), pp.3627-3632. 10.1002/pssc.200675752 - cea-02356035

\section{HAL Id: cea-02356035 https: / hal-cea.archives-ouvertes.fr/cea-02356035}

Submitted on 2 Dec 2019

HAL is a multi-disciplinary open access archive for the deposit and dissemination of scientific research documents, whether they are published or not. The documents may come from teaching and research institutions in France or abroad, or from public or private research centers.
L'archive ouverte pluridisciplinaire HAL, est destinée au dépôt et à la diffusion de documents scientifiques de niveau recherche, publiés ou non, émanant des établissements d'enseignement et de recherche français ou étrangers, des laboratoires publics ou privés. 


\title{
Determination of the positrons annihilation characteristics of the $\mathrm{UO}_{2}$ lattice
}

\author{
H. Labrim, M.-F. Barthe, A. Gentils*, P. Desgardin, G. Blondiaux \\ CERI-CNRS, 3A rue de la Férollerie, 45071 Orléans cedex 2, France
}

\author{
C. Corbel
}

LSI, Ecole Polytechnique, 91128 Palaiseau, France

\author{
J.P. Piron
}

DEN/DEC/SESC, CEA Cadarache, 13108 Saint Paul lez Durance, France

\begin{abstract}
Annealing of sintered polished $\mathrm{UO}_{2}$ disks at high temperature $\left(1700^{\circ} \mathrm{C}\right)$ has been performed in order to eliminate the defects created both during the sintering and the polishing of the disks. Several sets of such $\mathrm{UO}_{2}$ disks coming from different origins have been studied in the bulk using positron lifetime spectroscopy, and near the surface using a slow positron beam coupled with Doppler broadening spectrometry. They appear homogeneous and similar using positron annihilation spectroscopy. Results show the presence of negative ions, that may be negatively charged oxygen atom located in interstitial site. The positrons annihilation characteristics of the $\mathrm{UO}_{2}$ lattice have been determined and are equal to $\mathrm{S}_{\mathrm{L}}\left(\mathrm{UO}_{2}\right)=0.371$, $\mathrm{W}_{\mathrm{L}}\left(\mathrm{UO}_{2}\right)=0.078, \tau_{\mathrm{L}}\left(\mathrm{UO}_{2}\right)=169 \mathrm{ps}$.
\end{abstract}

PACS codes:

78.70.Bj Positron annihilation

61.72.Ji Point defects (vacancies, interstitials, color centers, etc.) and defect clusters 61.82.Fk Semiconductors

Keywords: positron annihilation, uranium dioxide, vacancy defects, annealing

*Corresponding author: A. Gentils; Tel.: +33 2382578 51; Fax: +33 2386302 71; E-mail address: gentils@cnrs-orleans.fr 


\section{INTRODUCTION}

The behavior of uranium dioxide under irradiation as nuclear fuel in fission reactors has been extensively studied by using different irradiation conditions and characterization techniques. ${ }^{1}$ Experimental studies are still necessary to determine the fundamental properties of defects that can be induced by irradiation such as their nature, formation energy, migration recombination energy, and so on... We propose to investigate vacancy defects in this material using positron annihilation spectroscopy.

Few results have been published concerning the study of uranium dioxide $\left(\mathrm{UO}_{2}\right)$ using positron annihilation spectroscopy. Upadhyaya et al have examined the variation of positron lifetime with particle size in $\mathrm{UO}_{2}$ powders. ${ }^{2}$ Both lifetime and Doppler broadening studies of $\mathrm{UO}_{2}$ are included in a study of the oxidation and hydriding of uranium by Howell et al. ${ }^{3}$ The influence of the uranium concentration at room temperature was studied by T. Troev et al using Doppler broadening and positron lifetimes' measurements. ${ }^{4}$ H.E. Evans et al have studied defect and inert gas behavior (krypton) in uranium dioxide pellets using a slow positron beam. ${ }^{5}$ In previous studies we have investigated vacancy defects induced by either polishing or helium implantation in sintered polished $\mathrm{UO}_{2}$ disks and their thermal evolution. ${ }^{6,7}$

But the annihilation characteristics, like the diffusion coefficient and the lattice and defects lifetimes, are not known in this material and have never been determined to our knowledge. In this work we have used both slow positron beam coupled with a Doppler broadening spectrometer and positron lifetime measurements using fast positrons to determine the positron annihilation lattice characteristics of $\mathrm{UO}_{2}$. Annealing at $1700^{\circ} \mathrm{C}$ has been done in order to reduce the number of defects created in the $\mathrm{UO}_{2}$ disks during their fabrication.

\section{EXPERIMENTAL DETAILS}

Several sintered disks of uranium dioxide $\left(0.2\right.$ at.\% $\left.{ }^{235} \mathrm{U}\right)$ have been produced by various labs (set G from the SICN company, France and sets B and L from the CEA Cadarache, France). The sintering conditions and the powder used could thus be different. All the disks have been polished and annealed during 24 hours at $1700^{\circ} \mathrm{C}$ under a wet $\mathrm{ArH}_{2}$ atmosphere in order to preserve their stoichiometry. The mean ratio $\mathrm{O} / \mathrm{U}$ measured by polarography is equal to $2.0051 \pm 0.0001$ for the disks of the set $\mathrm{G}$, and the mean density is $10.76 \pm 0.03 \mathrm{~g} . \mathrm{cm}^{-3}$. X-ray absorption spectroscopy measurements on a $\mathrm{G}$ set disk have shown that the surface of the disk is a thin layer of $\mathrm{U}_{4} \mathrm{O}_{9}$ (a few nm). ${ }^{8}$ The disk called Ga16 (from set G) has been chosen as a reference. Both the slow positron beam coupled with a Doppler broadening spectrometer and positron lifetime measurements were used for this study. 
The positron-electron momentum distributions were measured at $300 \mathrm{~K}$ by recording the Doppler broadening of the $511 \mathrm{keV}$ annihilation radiations. The low $\mathrm{S}$ and high $\mathrm{W}$ momentum annihilation fraction were recorded in the momentum range $(0-|2.80|) \times 10^{-3} \mathrm{~m}_{0} \mathrm{c}$ and $(|10.61|-|26.35|) \times 10^{-3} \mathrm{~m}_{0} \mathrm{c}$ respectively, as a function of the positron energy between 0.5 and $25.0 \mathrm{keV}$ by $0.5 \mathrm{keV}$ steps using a slow positron beam at the CERI-CNRS lab. ${ }^{9}$ The positron mean implantation depth in $\mathrm{UO}_{2}$ varies from $\sim 1$ to $\sim 570 \mathrm{~nm}$ in this energy range, as calculated for $\mathrm{Ge},{ }^{10}$ as the mean atomic number of $\mathrm{UO}_{2}\left(\mathrm{Z}_{\mathrm{UO} 2}=36\right)$ is close to the one of $\mathrm{Ge}$ $\left(\mathrm{Z}_{\mathrm{Ge}}=32\right)$.

Positron lifetime measurements were performed using a conventional fast-fast coincidence spectrometer with a time resolution of $230 \mathrm{ps}$. A ${ }^{22} \mathrm{Na}$ positron source was sandwiched between two identical samples, and the time interval between the two photons coming from the $\beta^{+}$decay and the positron annihilation was measured as the positron lifetime as a function of the temperature in the 15-600 K range. Approximately two million events were collected for each spectrum. The lifetime spectra, equal to $R \otimes \Sigma I_{i} \exp \left(-t / \tau_{i}\right)$, were analyzed using a modified version of the software PosFiT, ${ }^{11}$ as sums of exponential lifetime components $\tau_{\mathrm{i}}$ weighted by the intensities $\mathrm{I}_{\mathrm{i}}$, convoluted with a Gaussian resolution function $\mathrm{R}$. The average lifetime is the center of mass of the lifetime spectrum and can be calculated as $\tau_{\mathrm{av}}=\Sigma \mathrm{I}_{\mathrm{i}} \tau_{\mathrm{i}}$

\section{RESULTS}

The low (S) and high (W) momentum annihilation fractions were measured in the first micrometer from the surface of the disks as a function of the positron energy E. Results obtained on nineteen $1700^{\circ} \mathrm{C} / 24 \mathrm{~h} / \mathrm{ArH}_{2}$ annealed $\mathrm{UO}_{2}$ disks coming from the same set $(\mathrm{G})$ show similar behavior of $\mathrm{S}(\mathrm{E})$ and $\mathrm{W}(\mathrm{E})$ values. Only the results obtained on the disks named Ga16 and Ga17 are represented in the Fig. 1. S decreases and $\mathrm{W}$ increases rapidly as a function of the positron energy from 0.5 to $2.0 \mathrm{keV}$, and then more slowly up to $5.0 \mathrm{keV}$. They remain constant between 5.0 and $25.0 \mathrm{keV}$ and the $\mathrm{S}$ and $\mathrm{W}$ values of the Ga16 reference on the plateau are $\left(\mathrm{S}_{\text {ref, }} \mathrm{W}_{\text {ref }}\right)=(0.3713,0.0786)$. A modified version of VEPFIT, ${ }^{12}$ is used to fit the $\mathrm{S}(\mathrm{E})$ and $\mathrm{W}(\mathrm{E})$ curves between 2.5 and $25.0 \mathrm{keV}$ using one homogeneous layer model. A positron effective diffusion length $\mathrm{Leff}^{+}$of around $9 \mathrm{~nm}$ is obtained. It indicates that the $\mathrm{UO}_{2}$ disks can be considered as homogeneous as a function of the depth, and the $\mathrm{S}$ and $\mathrm{W}$ values found on the plateau are the annihilation characteristics of the bulk of the disks. 
Measurements of the $\mathrm{S}$ and $\mathrm{W}$ values of the other sets (B and L) give also the same results as the set $\mathrm{G}$ (Fig. 2). The $\mathrm{W}$ values as a function of the energy are not represented in the figure as they have the same opposite behavior as the $S$ one. No change is observed for the annihilation characteristics of the bulk of the disks whatever is the set, and $\mathrm{Leff}^{+}$values obtained for each set are given in Table I.

All these measures were done at $300 \mathrm{~K}$. Some measurements were also performed at lower temperatures in order to observe if the temperature can modify the detected defects distribution. No change has been observed whatever is the measurement temperature. Results are presented in the Fig. 3 only for the temperatures $35 \mathrm{~K}, 75 \mathrm{~K}$ and $300 \mathrm{~K}$. S decreases rapidly as a function of the positron energy from 0.5 to $3.0 \mathrm{keV}$, and then more slowly up to $5.0 \mathrm{keV}$. It remains constant between 5.0 and $25.0 \mathrm{keV}$. Only a difference can be observed at $0.5 \mathrm{keV}$ : $\mathrm{S}$ and $\mathrm{W}$ values change as a function of the temperature. The low (S) and high (W) momentum annihilation fractions have been measured as a function of the time at low temperature, and we have observed an increase (decrease) of S (W). The variation of S and W at low positrons energy is thus due to the adsorption of a contaminated layer at the surface of the sample, which is cold. This layer is desorbed when the sample is annealed up to the room temperature. A modified version of VEPFIT has also been used to fit the $S(E)$ and $W(E)$ curves between 1.5 and $25.0 \mathrm{keV}$ using one homogeneous layer model. The annihilation characteristics of the volume of the disks do not vary as a function of the temperature, as well as the positron effective diffusion length $\mathrm{L}_{\mathrm{eff}}{ }^{+}$that is equal to $7 \mathrm{~nm}$.

Positron lifetime measurements have been done on two samples of the G set annealed at $1700^{\circ} \mathrm{C}$ during 24 hours under a wet $\mathrm{ArH}_{2}$ atmosphere. A measure performed at $300 \mathrm{~K}$ give an average lifetime $\tau_{\mathrm{av}}$ equal to $168.7 \pm 1.1 \mathrm{ps}$, and a lifetime component $\tau_{1}$ of $168.7 \pm 1.1 \mathrm{ps}$ with an intensity $I_{1}$ of $100 \%$. The positron lifetime has also been measured as a function of the temperature, between $15 \mathrm{~K}$ and $575 \mathrm{~K}$ by $25 \mathrm{~K}$ steps (Fig. 4). The average lifetime $\tau_{\mathrm{av}}$ increases first slowly between 15 and $335 \mathrm{~K}$ from 165 ps to $169 \mathrm{ps}$, and then more quickly between 335 and $575 \mathrm{~K}$ from 169 to 187 ps. For measurement temperatures under $335 \mathrm{~K}$, only one lifetime component is obtained from the recorded lifetime spectra that increases from 165 to 169 ps between 15 and $335 \mathrm{~K}$. Above $335 \mathrm{~K}$ two components have been extracted. The lifetime $\tau_{1}$ of the shortest component increases from 169 to 175 ps between 335 and $575 \mathrm{~K}$. The lifetime $\tau_{2}$ of the longest component is equal to 475 ps at $335 \mathrm{~K}$ and tends toward $270 \pm 40$ 
ps with the increasing temperature. Its intensity $\mathrm{I}_{2}$ stays low until $400 \mathrm{~K}$ and varies from 2 to $10 \%$ after $400 \mathrm{~K}$.

The lifetime spectra recorded above $335 \mathrm{~K}$ have also been decomposed using a fixed value of $\tau_{2}$ equal to $270 \mathrm{ps}$. The lifetime $\tau_{1}$ of the shortest component is thus equal to $169 \pm 4 \mathrm{ps}$ and stays constant until $450 \mathrm{~K}$, then increases with the temperature up to $178 \mathrm{ps}$ at $575 \mathrm{~K}$. The $\mathrm{I}_{2}$ intensity is equal to $1 \%$ at $335 \mathrm{~K}$ and increases with the temperature up to $10 \%$ at $575 \mathrm{~K}$. These results show that a decomposition performed with two components is not sufficient. Decomposition of the lifetime spectra using three components have been performed, in particular with a lifetime $\tau_{2}$ of the longest component equal to $307 \mathrm{ps}$, which is the lifetime characteristic of a vacancy defect linked to the lack of an uranium atom in the $\mathrm{UO}_{2}$ lattice. ${ }^{13}$ The results are not acceptable.

Above $335 \mathrm{~K}$ the value of $\tau_{\bmod }$ (calculated as $1 / \tau_{\bmod }=I_{1} / \tau_{1}+I_{2} / \tau_{2}$ and obtained for a positron trapping model in only one vacancy) is higher than the lifetime measured at low temperature. This confirms that the positrons detect more than a trap in the virgin $\mathrm{UO}_{2}$ disks polished and annealed at $1700^{\circ} \mathrm{C}$ during 24 hours under a wet $\mathrm{ArH}_{2}$ atmosphere.

Several conclusions are extracted from these results. First of all only one annihilation state is detected at low temperature $(<335 \mathrm{~K})$ with a lifetime of $169 \pm 4 \mathrm{ps}$. Secondly the fact that a long component with a lifetime $\tau_{2}$ can be extracted above $335 \mathrm{~K}$ indicates that the positrons detect one or several vacancy traps (named $\mathrm{V}_{\mathrm{HT}}$, as vacancy detected at high temperature). The lifetime of these defects is not easy to obtain from the spectra, because the intensity $I_{2}$ is low, and it is maybe several vacancy defects with a low trapping rate. These vacancy traps with a lifetime higher or equal at $270 \mathrm{ps}$ are not detected at low temperature. This indicates that: (i) either these traps are created when the temperature increases and becomes higher than $335 \mathrm{~K}$ : the trapping in these defects begins to be in competition with the annihilation in the state detected at low temperature which has a lifetime of $169 \pm 4 \mathrm{ps}$; (ii) or another trap very active at low temperature $\left(\mathrm{T}_{\mathrm{LT}}\right)$ exists, and prevent the $\mathrm{V}_{\mathrm{HT}}$ defects detection. The trapping rate at these $T_{L T}$ traps decreases with the increasing temperature. This kind of variation is well known for the negatively charged defects trapping coefficient. ${ }^{14}$ The $\mathrm{T}_{\mathrm{LT}}$ traps characteristic lifetime is $169 \pm 4 \mathrm{ps}$. Moreover we have observed that the lifetime of the shortest component does not decrease when the positrons detect the $\mathrm{V}_{\mathrm{HT}}$ defects. It means thus that a trapping model with two states (the lattice and one $\mathrm{V}_{\mathrm{HT}}$ vacancy defect for example) is not available. This indicates that the annihilation state detected at low temperature cannot be the delocalized state of the lattice alone. From these lifetimes measures as a 
function of the temperature one can conclude that at least two types of traps are detected by the positrons: one which has a lifetime equal to $169 \pm 4$ ps prevails at low temperature $(<335 \mathrm{~K})$, and the other(s) is/are vacancy type, and is/are detected only above $335 \mathrm{~K}$.

\section{DISCUSSION}

The spatial distribution of defects seen by the positrons is homogeneous in the first micrometer from the surface as a function of the depth in the $1700^{\circ} \mathrm{C} / 24 \mathrm{~h} / \mathrm{ArH}_{2}$ annealed $\mathrm{UO}_{2}$ disks studied. The $\mathrm{S}$ and $\mathrm{W}$ positron annihilation characteristics in the volume of these disks do not vary whatever is the sample, the set or even the measurement temperature between 35 and $300 \mathrm{~K}$ (Fig. 1, 2 and 3). In particular the positron effective diffusion length $\mathrm{Leff}^{+}$stays around $10 \mathrm{~nm}$, which is a very low value compared to the value of the diffusion length obtained in other materials without defects $(100-300 \mathrm{~nm}) .{ }^{15}$ This suggests either the presence of an electrical field that can drive the positrons towards the bulk of the disk, or the trapping of the positrons at a defect, preventing them to diffuse back to the surface after their thermalization.

The variation of the average lifetime as a function of the temperature shows that the

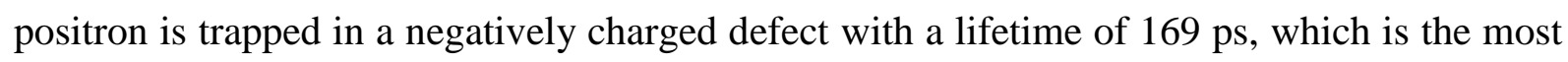
detected up to $335 \mathrm{~K}$. The nature of these traps could be either vacancy defects or negative ions defects.

It is important to note that these $\mathrm{UO}_{2}$ disks polished and annealed at $1700^{\circ} \mathrm{C} / 24 \mathrm{~h} / \mathrm{ArH}_{2}$ are overoxidised. Indeed a thin layer of $\mathrm{U}_{4} \mathrm{O}_{9}$ around $9 \mathrm{~nm}$ has been observed on these disks by X-ray absorption spectroscopy. ${ }^{8}$ Moreover the mean ratio $\mathrm{O} / \mathrm{U}$ measured by polarography is equal to $2.0051 \pm 0.0001$. This technique is based on the dissolution of the sample: an overconcentration of the surface cannot thus be observed. The $\mathrm{O} / \mathrm{U}$ ratio higher than 2 could be due to an overconcentration of the volume, and/or to the presence of an overoxidised layer. The overconcentration in oxygen induced by the presence of the $9 \mathrm{~nm}$ thick $\mathrm{U}_{4} \mathrm{O}_{9}$ layer over all the surface of these disks is approximately equal to $10^{18} \mathrm{~cm}^{-3}$. This value is negligible compared to the overconcentration revealed by the polarography measures, which is around $3.7 \times 10^{20} \mathrm{~cm}^{-3}$. These calculations prove that there is an oxygen excess in all the volume of the $\mathrm{UO}_{2}$ disks of the set $\mathrm{G}$, polished and annealed at $1700^{\circ} \mathrm{C}$ during 24 hours under a wet $\mathrm{ArH}_{2}$ atmosphere. This over-stoichiometry indicates that these disks are p-type semiconductors. ${ }^{16} \mathrm{It}$ suggests that the negatively charged defect detected by the positron is linked to the oxygen interstitial. If it is true, one can supposed that this defect is ionic. The trapping rate can be 
estimated at $300 \mathrm{~K}$ using the Eq. (1) where $\mathrm{Leff}^{+}$is the effective diffusion length obtained from the $\mathrm{S}(\mathrm{E})$ and $\mathrm{W}(\mathrm{E})$ data adjustments (Table I) and equal to $10.8 \mathrm{~nm}$ in the $\mathrm{G}$ set disks :

$$
\mathrm{Leff}^{+}=\left(\mathrm{D}^{+} /\left(\mathrm{K}_{\mathrm{IN}}+\lambda_{\mathrm{L}}\right)\right)^{1 / 2}
$$

where $\mathrm{D}^{+}$is the positrons diffusion coefficient in $\mathrm{UO}_{2}, \mathrm{~K}_{\mathrm{IN}}$ is the trapping rate around these negative ions, and $\lambda_{\mathrm{L}}$ is the positrons annihilation rate in the delocalized state of the $\mathrm{UO}_{2}$ lattice. $\mathrm{D}^{+}$and $\lambda_{\mathrm{L}}$ are not known in $\mathrm{UO}_{2}$. If the traps active at low temperature are negative ions, their lifetime is close to the characteristic lifetime in the $\mathrm{UO}_{2}$ lattice, and so $\lambda_{\mathrm{L}}$ is equal to $1 / 169 \mathrm{~s}^{-1}$. It is also supposed that $\mathrm{D}^{+}$is equal to $1.5 \mathrm{~cm}^{2} \cdot \mathrm{s}^{-1}$, the mean value obtained at $300 \mathrm{~K}$ in several metals. ${ }^{17}$ Thus the trapping rate is equal to $10^{12} \mathrm{~s}^{-1}$ at $300 \mathrm{~K}$ in the polished and annealed $1700^{\circ} \mathrm{C} / 24 \mathrm{~h} / \mathrm{ArH}_{2} \mathrm{UO}_{2}$ disks. If the interstitial oxygen type negative traps specific trapping coefficient is equal to the value determined at $300 \mathrm{~K}$ for the negatively charged antisite $\mathrm{Ga}_{\mathrm{As}}$ in GaAs which is $3 \times 10^{15}$ at.s ${ }^{-1},{ }^{15}$ the traps concentration in the $\mathrm{UO}_{2}$ disks from the set $\mathrm{G}$ is equal to $3 \times 10^{19} \mathrm{~cm}^{-3}$. If one supposes that an acceptor trap is linked to only one oxygen interstitial atom, the off-stoichiometry is around $4 \times 10^{-4}$. This value is 10 times lower than the one determined by polarography $\left(5 \times 10^{-3}\right)$. An off-stoichiometry equivalent to the one measured by polarography can be obtained for a specific trapping rate of $2.5 \times 10^{14}$ at.s $^{-1}$. Moreover some of the oxygen interstitials can help in the Willis clusters formation, ${ }^{18}$ that are typical defects of the over-oxidation of $\mathrm{UO}_{2}$ which contain two oxygen interstitials in a defect. This confirms that the active traps at low temperature are negative ions linked to the oxygen interstitial.

Above $335 \mathrm{~K}$ a second lifetime component appears and shows clearly the presence of vacancy defects. The trapping rate in these defects is negligible at low temperatures and stays low at higher temperature. This can be explained either because these vacancy defects are neutral and their trapping rate and concentration are lower than those of the negative ions, or because these defects appear only above $335 \mathrm{~K}$. Above $300 \mathrm{~K}$ Willis clusters composed of an oxygen divacancy and four oxygen interstitials could be formed. X-ray Photoelectron Spectroscopy (XPS) measures have been performed on an annealed $1300^{\circ} \mathrm{C} / 24 \mathrm{~h} / \mathrm{ArH}_{2} \mathrm{UO}_{2}$ disk, and then annealed at $670 \mathrm{~K}$ under vacuum using the setup where are done the lifetime measurements as a function of temperature. No overoxidation of the surface has been observed; this thus suggests that no Willis clusters have been introduced during our lifetime measurements performed in the same conditions (up to 575K). Moreover the vacancy defects formation energy in $\mathrm{UO}_{2}$ seems to be high according to the theory and the experimental results. ${ }^{19}$ It is thus unlikely that vacancy defects could be created at $335 \mathrm{~K}$. 
The positrons measurements performed on the different $\mathrm{UO}_{2}$ disks coming from different sets show that the annealing at high temperature $\left(1700^{\circ} \mathrm{C}\right)$ during 24 hours under a wet $\mathrm{ArH}_{2}$ atmosphere eliminates the detection of the defects created by both the sintering and the polishing of the disks. It also shows the presence of negative ions. The Rydberg states around the negative ions are not very deep traps for the positrons, in which they do not see free volume. Moreover the trapped positrons in the Rydberg state are far away from the ion centre (Rydberg radius 1-10 $\mathrm{nm},{ }^{15}$ ) and probe only the interstices. Thus the Rydberg states annihilation characteristics are similar to those of the lattice. ${ }^{15}$ Consequently the annihilation characteristics found in these polished and annealed $1700^{\circ} \mathrm{C} / 24 \mathrm{~h} / \mathrm{ArH}_{2} \mathrm{UO}_{2}$ disks, for temperatures lower or equal to $300 \mathrm{~K}$, could be those of the $\mathrm{UO}_{2}$ lattice: $\mathrm{S}_{\mathrm{L}}\left(\mathrm{UO}_{2}\right)=0.371$, $\mathrm{W}_{\mathrm{L}}\left(\mathrm{UO}_{2}\right)=0.078, \tau_{\mathrm{L}}\left(\mathrm{UO}_{2}\right)=169 \mathrm{ps}$.

Positrons lifetime in the $\mathrm{UO}_{2}$ lattice can be estimated using the linear dependence found for various semiconductors between the unit cell volume and the positron bulk lifetime: ${ }^{20} \tau_{\mathrm{L}}=\mathrm{C}_{1} \mathrm{x} \mathrm{a} 0^{3 / 2}$, where $\mathrm{a}_{0}$ is the unit cell volume in $\mathrm{nm}^{1.5}$ and $\mathrm{C}_{1}$ a constant equal to $543.8 \mathrm{ps} . \mathrm{nm}^{-1.5}$. Using the unit cell volume in $\mathrm{UO}_{2}$ that is equal to $5.47 \times 10^{-1} \mathrm{~nm}$, the positron lattice lifetime is found to be 220 ps. This value is higher than the one obtained in this work. One should note that this equation gives lattice lifetimes values 20 ps higher for $\mathrm{SiC}$ and $\mathrm{GaN}$. The difference is $50 \mathrm{ps}$ in $\mathrm{UO}_{2}$. This could be also explained by the high ionicity of $\mathrm{UO}_{2}$, equal to $0.93,{ }^{21}$ compared to those of $\mathrm{Si}$ or $\mathrm{Ge}$, equal to 0 .

\section{CONCLUSION}

Measures of Doppler broadening of the $511 \mathrm{keV}$ annihilation radiation performed with slow positrons show that the polished and annealed $1700^{\circ} \mathrm{C} / 24 \mathrm{~h} / \mathrm{ArH}_{2} \quad \mathrm{UO}_{2}$ disks are homogeneous and similar whatever is the set and the sample. The low positron effective diffusion length $\mathrm{Leff}^{+}$obtained and the variation of the lifetime as a function of the temperature can be explained by the presence of negative ions. We propose that these negative ions are negatively charged oxygen atom located in interstitial site. The positrons annihilation characteristics of the $\mathrm{UO}_{2}$ lattice have been determined: $\mathrm{S}_{\mathrm{L}}\left(\mathrm{UO}_{2}\right)=0.371$, $\mathrm{W}_{\mathrm{L}}\left(\mathrm{UO}_{2}\right)=0.078, \tau_{\mathrm{L}}\left(\mathrm{UO}_{2}\right)=169 \mathrm{ps}$. 


\section{ACKNOWLEDGEMENTS}

The authors are grateful to the Electricite de France (EDF) company and the research program on the long-term evolution of spent fuel waste packages of the CEA (PRECCI) for their financial support.

\section{REFERENCES}

${ }^{1}$ Hj. Matzke, Radiat. Eff. 64, 3 (1982); Nucl. Instr. Meth. B 32, 455 (1988).

${ }^{2}$ D.D. Upadhyaya, R.V. Muraleedharan, and B.D. Sharma, J. Nucl. Mater. 105, 82 (1982).

${ }^{3}$ R.H. Howell, C. Colmenares, and T. McCreary, J. Less-Common Metals 98, 267 (1984).

${ }^{4}$ T. Troev, I. Penev, and H. Protochristov, Physics Letters A 100, 221 (1984).

${ }^{5}$ H.E. Evans, J.H. Evans, P. Rice-Evans, D.L Smith, and C. Smith, J. Nucl. Mater. 199, 79 (1992).

${ }^{6}$ M.-F. Barthe, S. Guilbert, H. Labrim, P. Desgardin, T. Sauvage, G. Blondiaux, G. Carlot, P. Garcia, and J.P. Piron, Mater. Sci. Forum 445-446, 48 (2004).

${ }^{7}$ H. Labrim, M.-F.Barthe, P. Desgardin, T. Sauvage, G. Blondiaux, C. Corbel, and J.P. Piron, Applied Surface Science 252, 3256 (2006); 252, 3262 (2006).

${ }^{8}$ P. Martin, M. Ripert, and M. Freyss, "Caractérisation par spectroscopie d'absorption X de la stoechiométrie de surface de trois échantillons $\mathrm{UO}_{2}$ préparés par le CERI-CNRS/Orléans", mémoire CEA/SESC/LLCC 04-015, France (2004).

${ }^{9}$ P. Desgardin, L. Liskay, M.-F. Barthe, L. Henry, J. Briaud, M. Saillard, L. Lepolotec, C. Corbel, G. Blondiaux, A. Colder, P. Marie, and M. Levalois, Mater. Sci. Forum 363-365, 523 (2001).

${ }^{10}$ E. Soininen, J. Mäkinen, D. Beyer, and P. Hautojärvi, Phys. Rev. B 46, 13104 (1992).

${ }^{11} \mathrm{P}$. Kirkegaard and M. Eldrup, "POSITRONFIT: a versatile program for analysing positron lifetime spectra", Computer Phys. Commun. 3, 240 (1972).

${ }^{12}$ A. Van Veen, H. Schut, J. De Vries, R.A. Hakvoort, and M.R. Ijpma, AIP Conf. Proc. 218, 171 (1990).

${ }^{13}$ Hicham Labrim, PhD thesis, University of Orléans, France (2006).

${ }^{14}$ M.J. Puska, C. Corbel, and R.M. Nieminen, Phys. Rev. B 41, 9980 (1990).

${ }^{15} \mathrm{P}$. Hautojarvi and C. Corbel, "Positron spectroscopy of defects in metals and semiconductors", in Positron spectroscopy of solids, edited by A. Dupasquier and A.P. Mills $\operatorname{Jr}(1995)$.

${ }^{16}$ R.K. Willardson, J.W. Moody, and H.L. Goering, J. Inorg. Nucl. Chem. 6, 19 (1958). 
${ }^{17}$ C. Corbel, F. Pierre, K. Saarinen, P. Hautojärvi, and P. Moser, Phys. Rev. B 45, 3386 (1992).

${ }^{18}$ B.T.M. Willis, Journal Chem. Soc. Faraday Trans. 2, 83, 1073 (1987).

${ }^{19}$ J.P. Crocombette, F. Jollet, L. Thien Nga, and T. Petit, Phys. Rev. B 64, 104107 (2001); Hj.

Matzke, J. Chem.Soc., Faraday Trans. 2, 83, 1121 (1987); C. Meis and A. Chartier, J. Nucl.

Mater. 341, 25 (2005).

${ }^{20}$ H. Siethoff, Phys. Stat. Sol. (b) 205 (1998) R3.

${ }^{21}$ G.E. Murch and R.J. Thorn, Proceedings of an International Symposium on Thermodynamics of Nuclear Materials 1, 219 (1980). 


\section{TABLE CAPTION}

TABLE I: Positron effective diffusion length $\mathrm{Leff}^{+}$in the $\mathrm{G}, \mathrm{B}$ and $\mathrm{L}$ sets of $\mathrm{UO}_{2}$ disks as determined by adjusting $\mathrm{S}(\mathrm{E})$ and $\mathrm{W}(\mathrm{E})$ experimental data with a modified VEPFIT program, 12 using a model with one homogeneous layer. 


\section{FIGURE CAPTIONS}

FIG. 1: Relative low momentum fraction $S / S_{\text {ref }}$ (a) and relative high momentum fraction $\mathrm{W} / \mathrm{W}_{\text {ref }}$ (b) as a function of positron energy, and $\mathrm{S} / \mathrm{S}_{\text {ref }}$ as a function of $\mathrm{W} / \mathrm{W}_{\text {ref }}$ (c) in the Ga16 (squares) and $\mathrm{Ga} 17$ (triangles) $\mathrm{UO}_{2}$ disks polished and annealed during 24 hours at $1700^{\circ} \mathrm{C}$ under a wet $\mathrm{ArH}_{2}$ atmosphere. The solids lines are a fit of the (S, W) curves with a model of homogeneous layers using a modified version of VEPFIT. ${ }^{12}$

FIG. 2: Relative low momentum fraction $S / S_{\text {ref }}$ as a function of positron energy (a), and $S / S_{\text {ref }}$ as a function of $\mathrm{W} / \mathrm{W}_{\text {ref }}(\mathrm{b})$ in the $\mathrm{G}$ (squares), $\mathrm{L}$ (triangles) and $\mathrm{B}$ (stars) $\mathrm{UO}_{2}$ disks polished and annealed during 24 hours at $1700^{\circ} \mathrm{C}$ under a wet $\mathrm{ArH}_{2}$ atmosphere.

FIG. 3: Relative low momentum fraction $S / S_{\text {ref }}$ as a function of positron energy (a), and $S / S_{\text {ref }}$ as a function of $\mathrm{W} / \mathrm{W}_{\text {ref }}$ (b) in the $\mathrm{Ga} 48 \mathrm{UO}_{2}$ disk polished and annealed during 24 hours at $1700^{\circ} \mathrm{C}$ under a wet $\mathrm{ArH}_{2}$ atmosphere, obtained for different measurement temperatures $35 \mathrm{~K}$ (stars), 70K (triangles) and $300 \mathrm{~K}$ (squares).

FIG. 4: Temperature dependence of the positron lifetime spectra decomposition in $1700^{\circ} \mathrm{C} / 24 \mathrm{~h} / \mathrm{ArH}_{2}$ annealed $\mathrm{UO}_{2}$ disks of the set $\mathrm{G}$ : (a) average lifetime $\tau_{\mathrm{av}}$; (b) lifetime $\tau_{1}$ of the shortest component; (c) lifetime $\tau_{2}$ of the longest component; (d) its intensity $\mathrm{I}_{2}$. Lines are guide to the eyes. 


\begin{tabular}{|c|c|c|c|}
\hline & Set G & Set B & Set L \\
\hline $\mathrm{L}_{\text {eff }}{ }^{+}(\mathrm{nm})$ & 10.80 & 8.21 & 9.35 \\
\hline
\end{tabular}

Table I 


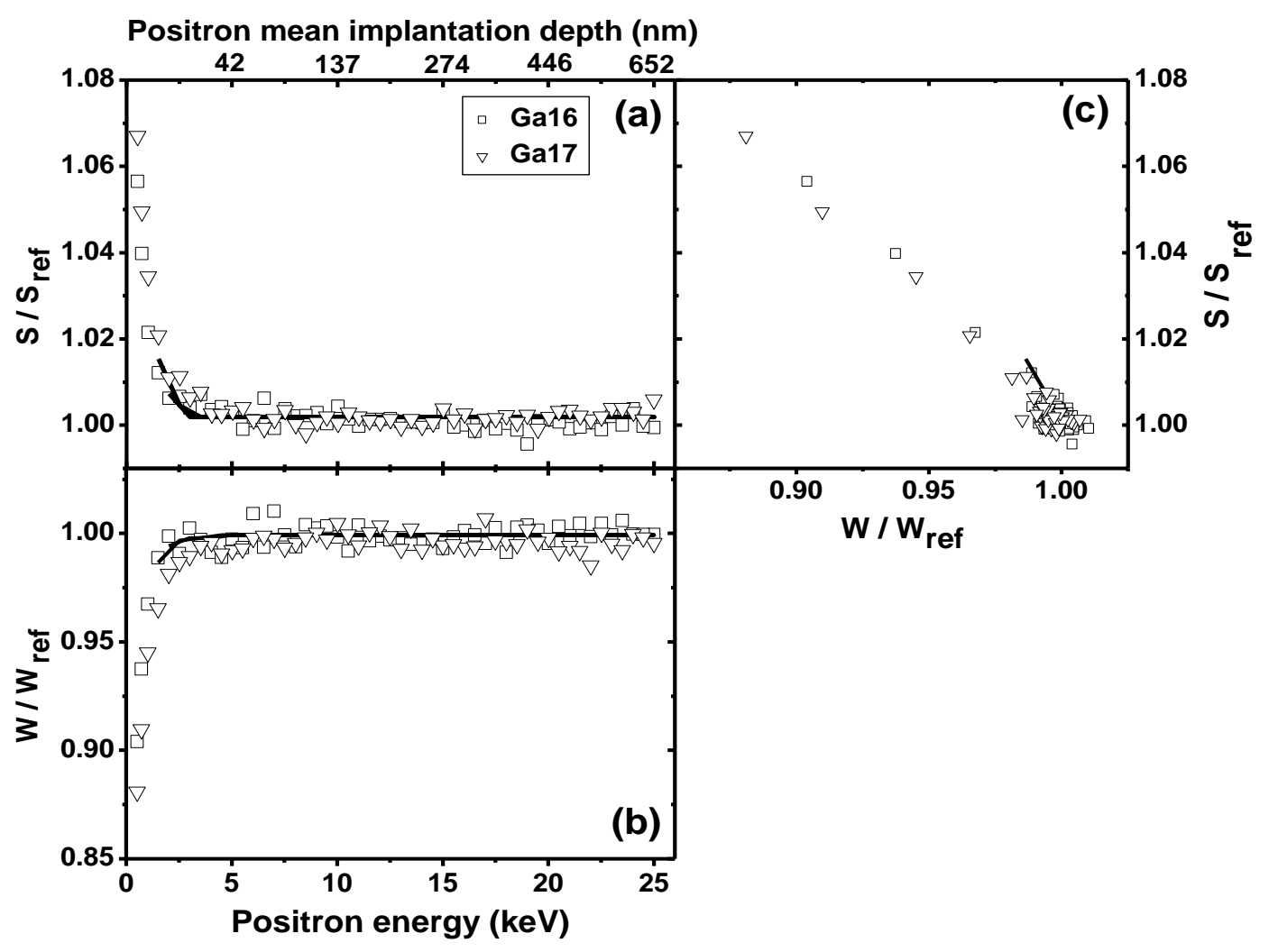

FIGURE 1 


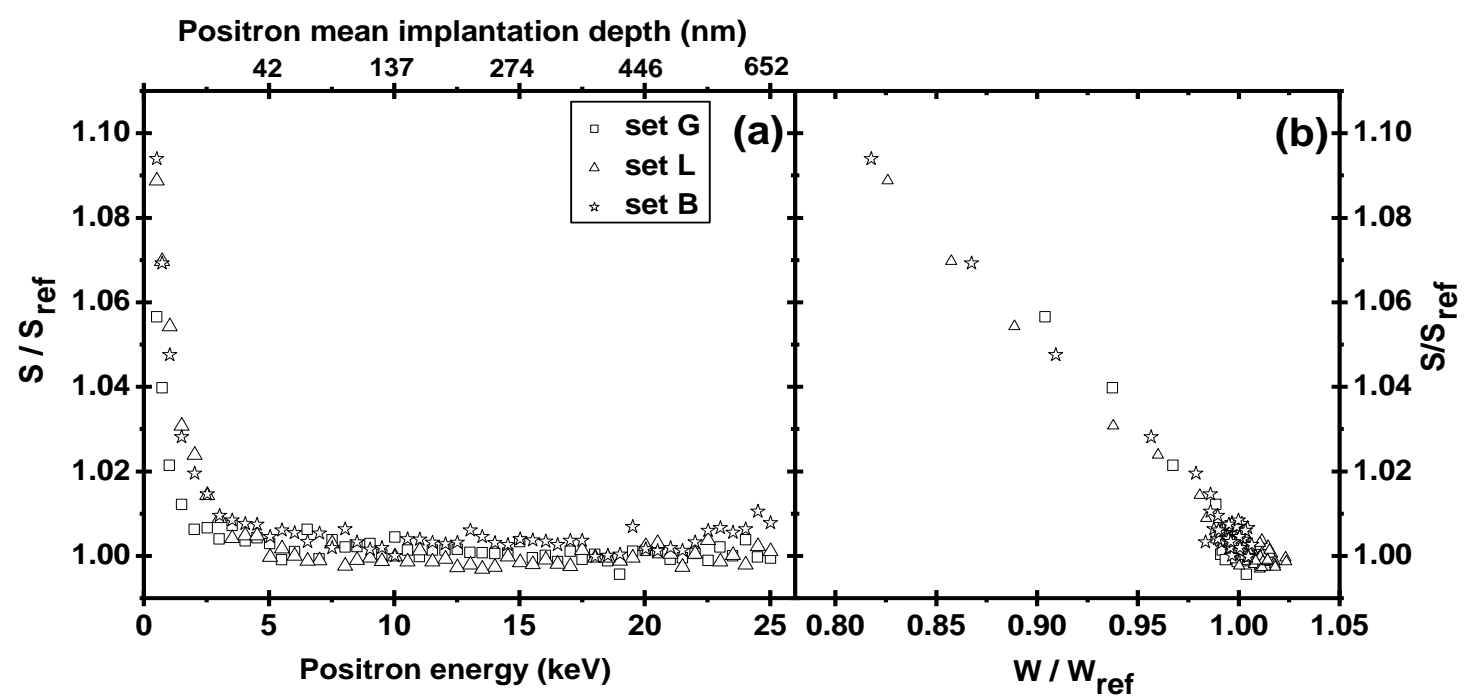

FIGURE 2 


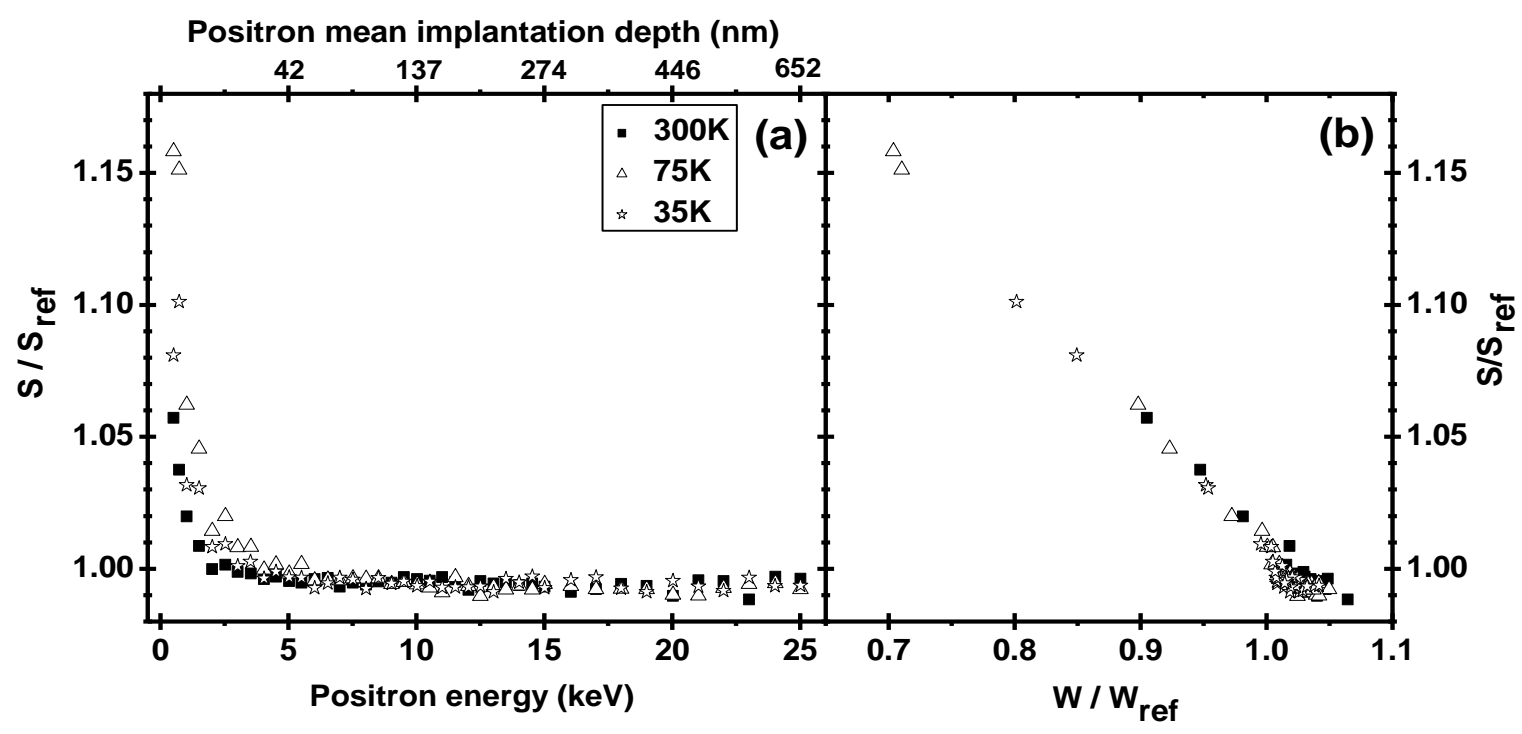

FIGURE 3 


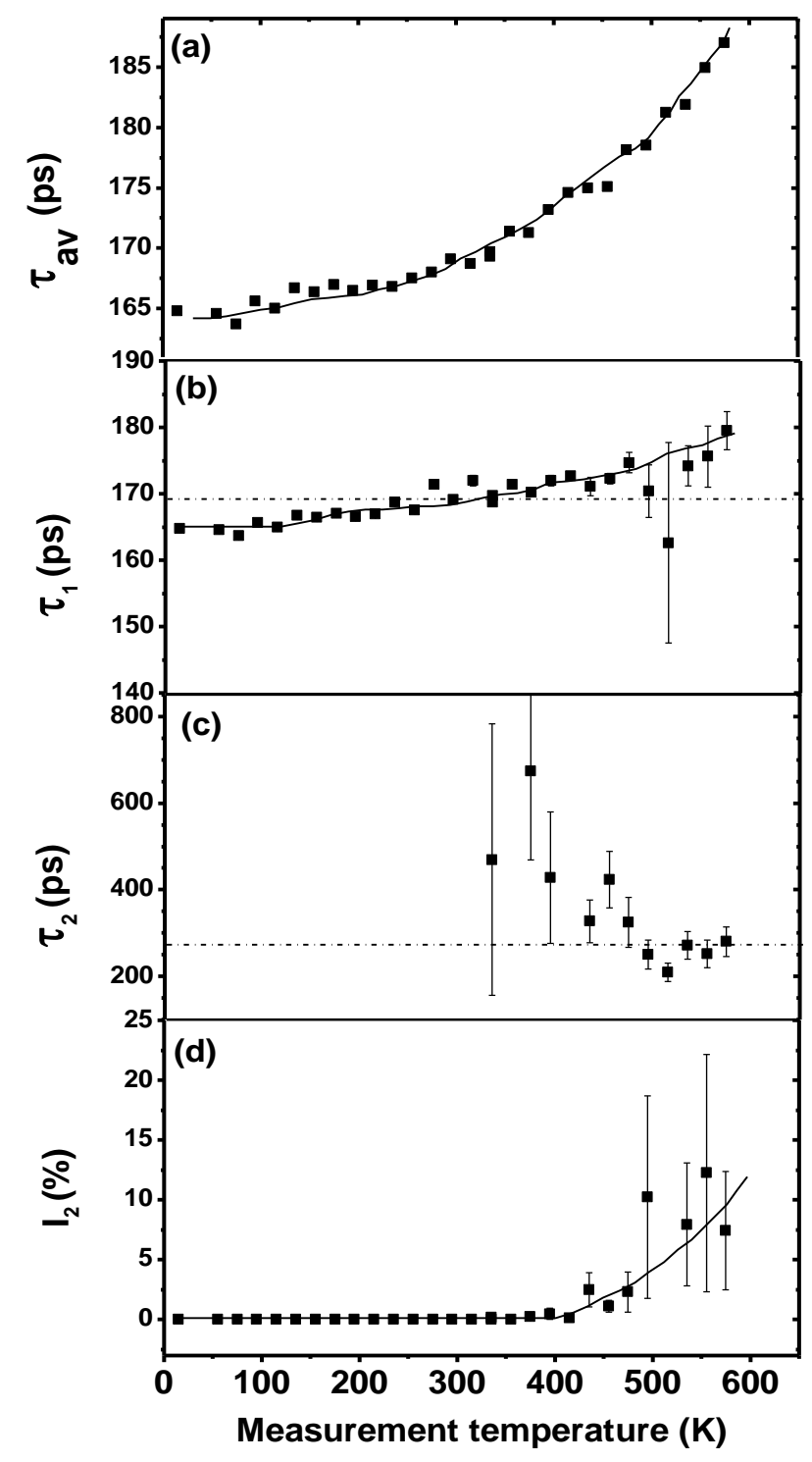

FIGURE 4 